\title{
Secondary Traumatic Stress and Burnout of North Korean Refugees Service Providers
}

\author{
Yeunhee Joyce Kim ${ }^{凶}$ \\ Department of Social Welfare, Daegu University, Center for Multiculturalism and Social Policy, Gyeongsan, Republic of Korea
}

\begin{abstract}
Objective The current study investigated the burnout and secondary traumatic stress of service providers for North Korean (NK) refugees based on the conceptual framework of theJob Demands-Resources (JD-R) model of workplace burnout.

Methods A cross-sectional self-administered survey was conducted with a national sample consisting of all 63 organizations in direct services to North Korean refugees. Of the estimated total number of 230 service providers comprising of social workers, psychotherapists, job counselors and paraprofessional counselors, 179 completed the survey, a $77.8 \%$ return rate.

Results While job resources such as personal commitment to work and organizational support indicated inverse relations to burnout, job demands such as workload, work environment and secondary traumatic stress (STS) showed a positive relationship to worker burnout. The STS were present in more than half of the respondents (51.3\%), of which $20.7 \%$ of them indicating a severe level of STS. The STS proved to be the most significant risk to worker burnout as it showed strong relations to all three dimensions of burnout.

Conclusion Structural issues of chronic work overload and poor work environment need to be addressed to reduce staff burnout. STS is a serious occupational hazard in working with North Korean refugees.

Psychiatry Investig 2017;14(2):118-125
\end{abstract}

Key Words Professional burnout, Refugees, Secondary traumatic stress, North Korean.

\section{INTRODUCTION}

Burnout is a major concern in the human service field in general, described as a prolonged response to chronic emotional and interpersonal stressors on the Human service workers are highly susceptible to stress and burnout ${ }^{1-3}$ due to being in an emotionally demanding relationship with a population exposed to a high level of stress without adequate resources. ${ }^{4,5}$ The caregivers of the traumatized population in particular are reported to be at an increased risk ${ }^{3,6,7}$ by becoming traumatized indirectly from the trauma materials shared by their clients. Secondary traumatic stress (STS) is conceptualized as reactions to the emotional demands on human service providers from exposure to the traumatic images, affect and memories expressed by trauma survivors. ${ }^{8}$ Service providers working with North Korean refugees in South Korea

Received: July 7, 2016 Revised: July 7, 2016

Accepted: July 15, 2016 Available online: March 6, 2017

$\triangle$ Correspondence: Yeunhee Joyce Kim, PhD

Department of Social Welfare, Daegu University, Center for Multiculturalism and Social Policy, 200 Daegudae-ro, Jillyang-eup, Gyeongsan 38453, Republic of Korea

Tel: +82-53-850-6317, Fax: +82-53-850-6319, E-mail: yeunheekim@daegu.ac.kr (a) This is an Open Access article distributed under the terms of the Creative Commons Attribution Non-Commercial License (http://creativecommons.org/licenses/bync/4.0) which permits unrestricted non-commercial use, distribution, and reproduction in any medium, provided the original work is properly cited. fit the high-risk profile for burnout due to the fact that they work with highly traumatized and resource-poor clientele while they try to deal with multi-layered needs of their clients through a nascent service delivery system without adequate support.

Since 2006, the South Korean government has made significant changes in its social policies and programs on North Korean refugee resettlement assistance, shifting its focus from a simple administration oflump sum cash grants at the beginning of resettlement to provision of extensive resettlement services for up to five years from arrival. ${ }^{9}$ The new service infrastructure of a one stop service center was established nationwide in 2009 in a contract with many homegrown service agencies for North Korean refugees to meet a full gamut of service needs ranging from initial community orientation to job training and placement as well as health and mental health care.

While the new service delivery system was installed to pay greater attention to unmet needs in the North Korean refugee community, there has been a clear absence of interest in the workforce that bears the burden of serviceimplementation with inadequate resources and an increased bureaucratic red tape and paperwork common in government contracts. Additionally, the short funding cycle of an annual contract re- 
newal makes it difficult for agencies to invest in organizational capacity such as clinical supervision and better worker compensation, all of which increases the risk of staff burnout. Therefore, it is imperative to conduct an empirical study to investigate the extent of staff burnout among NK service providers and the factorscontributing to the problem as the new service delivery system is still in the formative stage of implementation. In particular, the extent of secondary traumatic stress and its contribution to the burnout is of concern here as service providers deal with trauma materials on a daily basis without any systemic recognition of the occupational hazard of working with the traumatized population.

The findings of the current study begin toidentify the primary causes or correlates of burnout in service providers for North Korean refugees, with the goal of providing policy makers and management with empirical evidence as to points of intervention and intervention strategies to prevent staff burnout. ${ }^{2}$ The outcome of the present study may also shed light inunderstanding burnout of many service providers working with traumatized population in other countries and different cultural contexts.

\section{Research on service providers for North Korean refugees}

While there has been a significant amount of empirical research on North Korean refugees due to the extent of trauma they were exposed to in North Korea and during their flee, ${ }^{10-12}$ little research has been conducted on service providers for North Korean refugees, even though there have been anecdotal accounts of a high level of burnout and high staff attrition rates among the service providers for North Korean refugees. ${ }^{13-15}$ A search through the Research Information Sharing Service (RISS) generated only three related studies on NK service providers: one on staff burnout and the other two on jobsatisfaction and job demands. ${ }^{14-16}$ The previous studies indicated that personal ego resiliency and organizational support of clinical supervision and training are protective factors that mediate staff burnout, while heavy workload, poor compensation, and unique character traits of North Korean refugees were identified as sources of job stress. ${ }^{14,15}$ However, they did not investigate the effect of secondary trauma in the course of care provision. On the other hand, Kim and Kim ${ }^{16}$ investigated the correlates of the job satisfaction of NK service providers and found the exposure to trauma materials their clients share may be a significant threat to employee well-being.

With a dearth of empirical research on NK service providers, it is imperative that this study investigate the factors that may be related to burnout among service providers for North Korean refugees and the effect of secondary traumatic stress in particular. Findings have yielded some empirical evidence that inform the development of new programs andpolicies for prevention of STS and burnout among service providers for North Korean refugees.

\section{Burnout and personal, organizational and community factors}

\section{The Job Demands-Resources model as conceptual framework}

The current study attempted to better understand the complex interaction of the multiple factors that contribute to the burnout of service providers for North Korean refugees by applying the Job Demands-Resources (JD-R) model of workplace burnout as a conceptual framework. This well researched model describes two critical forces that affect employee wellbeing: job demands and job resources. Job demands are defined as "physical, psychological, social or organizational aspects of the job that require sustained physical and/or psychological effort" by the individual such as work overload, unfavorable physical environment, and unfavorable emotional and financial reward. ${ }^{4,17,18}$ In the current study, secondary traumatic stress (STS) is included as a salient job demand unique to the work with North Korean refugees. ${ }^{8}$ A few studies on the relationship between STS and burnout showed a significant correlation between the two. ${ }^{19,20}$ Job resources refer to "physical, psychological, social, and organizational aspects of the job that are functional in achieving work goals or reduce job demands ${ }^{17}$ such as personal self-efficacy and commitment, ${ }^{18}$ professional environments, and formalized service networks in the community. ${ }^{14,17}$ Previous research has demonstrated the protective effects of job resources against staff burnout. ${ }^{3,21}$

\section{Job demands and burnout}

Job demand such as workoverload, limited support, and role conflict has been a strong contributing factor to burnout. ${ }^{2,17}$ Work overload, role ambiguity, poor financial compensation have been mentioned as most common stresses of working in programs for North Korean refugees that are related with staff burnout. $^{14,15}$

\section{Secondary traumatic stress and burnout}

The current study investigated the relationship between STS as a job demand unique to working with NK refugees and burnout in NK service providers. In recent years, the notions of secondary and vicarious traumatization have drawn the attention of many professionals working with traumatized population as it becomes viewed as an occupational hazard. ${ }^{4,22}$ Vicarious trauma is theorized to be thecumulative transformative effects upon the clinician associated with workingwith trauma victims. ${ }^{23}$ Even though compassion fa- 
tigue and secondary traumatic stress (STS) have been frequently used interchangeably, compassion fatigue has been described in the literature as 'a form of caregiver burnout' as it incorporates the symptoms of Post-Traumatic Stress Disorder (PTSD), and components of burnout which are conceptually distinct constructs. ${ }^{22,24}$ Secondary traumatic stress (STS), on the other hand, is defined as a syndrome of symptoms identical to those of PTSD, with three constructs of symptoms of intrusion, avoidance, and arousal. ${ }^{22,24}$ This study chose the concept of STS to describe and measure the impact of working with traumatized North Korean refugees on service providers.

STS is understood as the natural consequence of caring for traumatized people and being affected by the traumatic experiences of the cared for. ${ }^{25}$ In addition to exposure to traumatized individuals, the chronicity of trauma work, as well as the individual's personal capacitiessuch as ego resiliency and self-efficacy were related to STS. ${ }^{7,26}$ The effects of STS are believed to produce an array of psychological, social and physical reactions ${ }^{4}$ such as higher risk of poor work performance, strains in the staff-client relationship, and high staff turnover. However, fewer empirical studies investigated the direct relationship between STS and burnout, even though burnout was mentioned frequently in association with working with traumatized populations. ${ }^{3,26,27}$ A few studies on the relationship between STS and burnout showed close relationships between STS and burnout. ${ }^{19,20}$ In both studies, STS was related more closely with emotional exhaustion and depersonalization than lack of personal achievement, which are three sub-constructs of the Maslach Burnout Inventory (MBI).

\section{Job resources and burnout}

Job resources are available at personal, organizational and community levels. ${ }^{17}$ Previous research has demonstrated the protective effect of job resources on staff burnout. ${ }^{2,3,21}$ Personal resources may be reflected in one's commitment to and involvement with the organization and were negatively associated with burnout. ${ }^{2}$ Organizational resources such as professional climate in an organization, positive perception of peer and supervisory support demonstrated a significant protective effect against burnout. ${ }^{28} \mathrm{~A}$ number of studies also show that positive perception of community resources is associated with lower worker burnout. ${ }^{14,28}$

\section{Demographic factors and burnout}

Previous research reported significant associations between burnout and the worker's demographic factors such as length of employment, education, age, gender, and number of work hours. $13,14,20,29$ Age and length of employment were more consistent in their inverse relationship with burnout. Burnout and other demographic variables showed less clear relationships to one another. ${ }^{1}$ However, as the present study serves as the very first attempt to investigate burnout in the NK field, the roles of these common demographic factors were explored.

\section{METHODS}

\section{Research design and sample}

The current research was conducted: 1) to investigate the extents of secondary traumatic stress (STS) and the burnout among service providers for North Korean refugees; 2) to identify correlates of worker burnout. It utilizes the Job Demands-Resources (JD-R) of workplace burnout as conceptual framework for the analysis. The job demands variables include the amount of work exposure measured by part-time and full-time status, the job stress level, and the secondary traumatic stresslevel. The job resources variables include personal commitment to the organization, the organizational and the community resource levels.

This study takes a cross-sectional approach with a self-administered survey for data collection from a national sample of service providers for North Korean refugees comprising of social workers, psychotherapists, job counselors and paraprofessional counselors. This study protocol and consent forms were verified and approved by the Institutional Review Board of the Daegu University. Of the estimated total number of 230 service providers at 63 organizations, 179 service providers completed the survey, a $77.8 \%$ return rate, which is a more than acceptable rate for survey research. ${ }^{30}$ The data were collected from November 8 to December 2, 2010.

The respondents comprised of 120 women (67\%) and 59 men $(33 \%)$,which is consistent with the gender breakdown of the workforce in the field. $82 \%$ of the respondents majored in social work and the rest in counseling (8\%) and teaching (10\%). The average age of the respondents was 32.4 years and $50.8 \%$ of the sample was in their 20 's. Most respondents had a college-level education (78.8\%) followed by graduate degree holders (19.6\%). Most respondents work full time for North Korean clients (93.3\%). The work force is relatively new in the field and young as indicated by an average length of stay in the field of 20.95 months. The organizations the respondents work for are comprised of the Hana Center, the one-stop service center for NK refugees (73.7\%), multi-service community center with NK service component (19.6\%), other NGOs (9.5\%), and NK NGOs (1.7\%).

\section{Measures}

\section{Burnout}

This study measured burnout by the Korean version of the 
Maslach Burnout Inventory (MBI). The MBI is a 22-item inventory with a 7 point Likert-type scale $(0=$ never, $6=$ every day). It is comprised of three subscales: nine items for emotional exhaustion (EE), five items for depersonalization (DP), and eight items for lack of personal accomplishment (PA). High scores on EE and DP and PA indicate high burnout. The MBI has demonstrated high internal consistencies in previous studies and for the current study, the Cronbach a's are 0.86 for EE, 0.80 for DP, and 0.81 for PA.

Job demands. The Job Stress Inventory was used to measure the perception of job demands. The measure was originally developed by Jayaratne and Chess ${ }^{31}$ and adapted into Korean by Baek. ${ }^{32}$ The scale is a 27 item inventory with a 5 point Likert-type scale and comprised of four sub-constructs: role ambiguity, workload, sense of achievement, and work environment. Higher scores on role ambiguity, workload, and sense of achievement and lower score on work environment indicate greater levels of job stress. The Cronbach $\alpha$ of this inventory for the current study was 0.81 and the Cronbach $\alpha$ of four sub-constructs were 0.73 for role ambiguity, 0.84 for workload, 0.54 for sense of achievement, and 0.71 for work environment.

\section{Secondary trauma stress}

The 17 item Secondary Traumatic symptoms (STS) inventory developed by Bride et $\mathrm{al}^{24}$ and adapted by Park ${ }^{33}$ into Korean was used to measure the extent of STS, a job demand unique to NK service providers working with traumatized individuals. The inventory is a 5 point Likert scale and comprised of three constructs: intrusive thoughts, avoidance, and hyper-arousal. The Cronbach $\alpha$ of the original STS inventory was 0.93 and in the current study the Cronbach $\alpha$ is 0.93 .

\section{Job resources-personal level}

The job resources at the personal level were operationalized as personal commitment to and psychological involvement with the organization and measured by the Organizational Commitment Questionnaire (OCQ). The questionnaire was originally developed by Porter, Steers, Mowaday and Boulian ${ }^{34}$ and adapted into Korean by $\mathrm{Kim}^{35}$ and is comprised of 15 items on a 5-point Likert scale with items such as "I am willing to put in more than average effort for my agency," "The values I aspire to are similar to those of the agency," "I am glad to have chosen to work for this organization." The Cronbach $a$ of the scale in the current study is 0.90 .

\section{Job resources-organizational level}

The respondents' perception of the organizational resource level was assessed by the four items questionnaire developed by Yoon et al. ${ }^{14}$ The measure is comprised of the respondents' perception of the professional competence in themselves and their colleagues, professional development opportunities within the organization and through outside educational programs. The higher score indicates a higher level of subjective perception of organizational resource within the organization. The Cronbach $\alpha$ of the scale in the current study is 0.79 .

\section{Job resources-community level}

Community resource was measured by four questions on community resources developed by Yoon et al. ${ }^{14}$ The measure assesses the respondents' perception of the level of community resources in terms of adequacy of inter-agency collaboration and coordination, the level of services and funding, biases and resistance of the community residents to the NK services, and the lack of cooperation among service providers. The Cronbach $\alpha$ of the measure in Yoon et al. ${ }^{14}$ was 0.63 and in this study it is 0.86 .

\section{Socio-demographic variables}

Socio-demographic information such as gender, age, education level, length of work experience in the NK service field, full/part time status was also collected.

\section{Statistical analysis}

Data analysis was performed using the Statistical Package for the Social Sciences (SPSS version 18.0). Univariate statistics

Table 1. Descriptive statistics of burnout and secondary traumatic stress (STS) (N=179)

\begin{tabular}{llll}
\hline & Severity & Freq. (\%) \\
\cline { 2 - 4 } & Severe (49 \& over) & $37(20.7)$ \\
\multirow{2}{*}{ STS } & High (44-48) & Moderate (38-43) & $15(8.4)$ \\
& Mild (below 37) & $41(22.9)$ \\
& Clinical cut-off point of 38 \& higher & $86(48.7)$ \\
& Below cut-off point & $93(51.3)$ \\
& \multicolumn{2}{c}{ Mean } & $86(48.7)$ \\
\hline \multirow{2}{*}{ Burnout } & S3.12 & SD & Min. \\
\hline
\end{tabular}


were used to establish the study's sample. Bivariate analysis of Pearson's correlations was used to determine the direction and the size of relationship and also to rule out multicolinearity between the variables. Three multiple regression analyses were conducted as each aspect of burnout (EE, DP, PA) was regressed on the predictor variables.

\section{RESULTS}

\section{Descriptive statistics}

While the respondents evaluated their personal commitment to work relatively high, they rated organizational and community resource levels much lower. They experienced job stress the most from workload followed by the work environment. Secondary traumatic symptoms were present in more than half of the respondents (51.3\%), of which $20.7 \%$ of them indicating a severe level of STS, $8.4 \%$ in the high level, and $22.9 \%$ in the moderate as presented on the Table 1 . The respondents in the current study indicated that they had experienced a very high level of burnout as the mean burnout score met the criterion of high burnout based on the MBI measure. $^{36}$

\section{Bivariate analysis}

Pearson's correlation coefficients between the main variables were obtained to determine the direction and the size of relationship and also to rule out multicolinearity between variables. The correlation between many predictive variables and the outcome variables reached statistical significance and the directions were as expected. None of the relationships between the variables was higher than 0.5 , ruling out multicoliniarity between any of those variables.

\section{Multivariate results}

To examine the correlation of predictor variables to each of three dimensions of burnout as suggested by the developers of the MBI measure, ${ }^{36}$ multiple regression analyses were conducted on the three sub-dimensions of burnoutand presented in Table 2.

\section{Emotional exhaustion}

The first regression analysis conducted to examine the relationships between the predictor variables and EE showed that the regression model explained $47 \%$ of EE and four predictors showed significant relationships with $\mathrm{EE}$. The respondents indicated a lower level of EE when they have a longer work experience and a higher level of personal commitment

Table 2. Results of three regression analyses of the MBI subscales

\begin{tabular}{|c|c|c|c|c|c|c|}
\hline \multirow{2}{*}{ Model } & \multicolumn{2}{|c|}{ Emotional exhaustion } & \multicolumn{2}{|c|}{ Depersonalization } & \multicolumn{2}{|c|}{ Lack of achievement } \\
\hline & $\beta$ & $\mathrm{t}$ & $\beta$ & $\mathrm{t}$ & $\beta$ & $\mathrm{t}$ \\
\hline \multicolumn{7}{|l|}{ Demographics: } \\
\hline Gender $^{\dagger}$ & -0.07 & -1.18 & 0.05 & 0.79 & -0.01 & -0.16 \\
\hline Age & -0.10 & -1.45 & -0.06 & -0.74 & -0.09 & -1.06 \\
\hline Education & 0.05 & 0.79 & 0.07 & 1.04 & 0.02 & 0.22 \\
\hline Time in the NK field & -0.12 & $-2.08^{*}$ & -0.10 & -1.44 & -0.03 & -0.36 \\
\hline Full time/part time $e^{\ddagger}$ & -0.01 & -0.09 & -0.04 & -0.56 & -0.04 & -0.52 \\
\hline \multicolumn{7}{|l|}{ Job resources } \\
\hline Personal & -0.25 & $-3.38^{* *}$ & -0.18 & $-2.16^{*}$ & -0.11 & -1.30 \\
\hline Organizational & -0.06 & -0.93 & -0.03 & -0.36 & -0.24 & $-2.95^{* *}$ \\
\hline Community & -0.04 & -0.63 & -0.05 & -0.78 & -0.08 & -1.14 \\
\hline \multicolumn{7}{|l|}{ Job demands } \\
\hline STS & 0.29 & $4.65^{* * *}$ & 0.32 & $4.39^{* * *}$ & 0.24 & $3.19^{* *}$ \\
\hline Role ambiguity & -0.10 & -1.74 & 0.04 & 0.62 & 0.12 & 1.78 \\
\hline Workload & 0.36 & $5.58^{* * *}$ & 0.17 & $2.33^{*}$ & -0.06 & -0.74 \\
\hline Sense of achievement & 0.05 & 0.71 & 0.16 & $2.26^{*}$ & 0.18 & $2.37^{*}$ \\
\hline Work environment & 0.05 & 0.69 & 0.00 & -0.02 & -0.17 & $-2.01^{*}$ \\
\hline Adj. $R^{2}$ & \multicolumn{2}{|c|}{0.47} & \multicolumn{2}{|c|}{0.32} & \multicolumn{2}{|c|}{0.25} \\
\hline F value & \multicolumn{2}{|c|}{$12.989^{* * *}$} & \multicolumn{2}{|c|}{$7.23^{* * *}$} & \multicolumn{2}{|c|}{$5.55^{* * *}$} \\
\hline Significance & \multicolumn{2}{|c|}{0.000} & \multicolumn{2}{|c|}{0.000} & \multicolumn{2}{|c|}{0.000} \\
\hline
\end{tabular}

${ }^{*} \mathrm{p}<0.05,{ }^{* *} \mathrm{p}<0.01,{ }^{* * *} \mathrm{p}<0.001,{ }^{\dagger}$ dummy variable: maleasreference group, ${ }^{*}$ full time as reference group. MBI: maslac burnout inventory, NT: North Korea, STS: secondary traumatic stress 
to the organization. They also showed a higher level of EE when they endorsed higher levels of workload and STS.

\section{Depersonalization}

The second regression analysis for DP explained 32\% of DP. No socio-demographic variable showed any significant relation to DP. The respondents indicated a higher level of DP when they endorsed lower personal commitment to the organization, higher STS, higher levels of job stresses from workloadand a diminished sense of achievement.

\section{Lack of personal accomplishment}

The third regression analysis for PA explained 25\% of PA. No socio-demographic variables had a significant relationship to PA. Among the resource variables, the organizational resource variable showed inverse relationship to PA, while three job demands variables-STS, sense of achievement, and work environment- showed a significant inverse relationship with PA.

The findings of this study show that the JD-R model explains the sub-dimensions of emotional exhaustion (EE) and depersonalization (DP) better than lack of personal achievement (PA). The demographic variables such as gender, age, educational level, part/full time status did not show any significant relationship with burnout except the relationship between length of work experience in the NK service field and EE. Among the three job resource variables, personal commitment proved to be related to EE and DP. A greater number of job demand variables showed significant relationships with worker burnout. The STS proved to be a consistent predictor of all three dimensions of burnout. Heavy workload showed a relationship with higher level of EE and DP, suggesting that work pressure may cause not only emotional exhaustion but also detachment from work. Structural issues such as lower organizational resource and the poor work environment contributed to a diminished sense of PA.

\section{DISCUSSION}

There has been a dearth of research on the North Koreanservice providers even though they are instrumental in successfully implementing the policies and programs for North Korean refugees. The present study is one of the first attempts to investigate secondary traumatic stress and burnout experienced by NK service providers and was conducted using the Job Demands-Resources model of workplace burnout. The findings of the present study are generalizable as over $70 \%$ of the entire NK service providers in the field participated in the survey.

In regards to job stressors, the results suggest that the re- spondents found the structural conditions of their work such as heavy workload and unfavorable work environment more stressful than psychosocial aspect of their job like role ambiguity and low sense of achievement. The results are similar to the previous research findings of heavy workload, long and unpredictable work hours, inadequate supervision and training opportunity being major sources of burnout. ${ }^{14,15}$ The secondary traumatic stressproved to be a potent job demand as more than half of the survey respondents indicated a clinical level of STS and one out of five respondents had a severe condition of STS. These findings are consistent with previous study findings of chronic exposure to trauma material being an occupational hazard of providing direct services to traumatized population..$^{22,37}$ It is an important contribution of this study to provide a quantifiable evidence for trauma being a serious work hazard for service providers who work with North Koreans. There was no difference in STS level by gender or by the type of organization service providers worked in. However, there was a dose response relationship as full time staff showed a higher level of STS than part-time staff. Staff from North Korea indicated a higher level of STS than South Korea-born staff, suggesting that previous exposure to trauma increases susceptibility to STS.

The respondents turned out to be in the category of high burnout $^{36}$ and placed in the second highest of 27 groups of human service providers researched in the U.S. with the same instrument, MBI. ${ }^{29}$ The study findings of Yoon et al. ${ }^{14}$ supported the observation of a high level of burnout of NK service providers. Service providers' personal commitment to serving North Korean refugees seems to be a very significant protective factor to staff burnout. On the other hand, heavy workload and STS were two major risks to staff burnout. The findings of the current study are consistent with the other research findings in that personal commitment to work are predictive of lower burnout ${ }^{14}$ and perception of greater pressure on the job had significant relation with higher burnout. ${ }^{1,2,7,17,20}$

Notably, STS is the factor that showed consistent and strong relationships with all three dimensions of burnout. STS was more closely related with EE and DP than PA as in the findings of other research..$^{19,20}$ The result may suggest that service providers may experience emotional exhaustion and try to cope with high STS by emotionally detaching themselves from their clients when they are exposed to excessivetrauma materials. The service providers may deal with the source of secondary traumain the same way as trauma victims avoid and disengage themselves from any stimuli that may trigger re-experiencing trauma-related reactions.

A few particularly noteworthy findings related to research, policy and practice led to various implications that follow. 
First, current study findings suggest thatmore favorable working conditions need to be created in order to retain the workforce, the relatively young workforce who got drawn to the work due to their personal commitment to services for North Korean refugees. A longer term contract and better worker compensation is warranted for successful implementation of resettlement policy and programs for North Korean refugees. Qualified mental health professionals should be hired to provide mental health treatment for refugees with serious mental health issues, instead of relying on the generalist social workers for a wide range of services in resettlement assistance.

The practice implications of the results of this study include the following. First, the current findings demonstratethat different job resources are related to different aspects of burnout. Personal commitment to the organization, psychological in nature, may help mitigate the emotional aspects of burnout such as emotional exhaustion and depersonalization. In contrast, organizational support, structural in nature such as supervision and educational opportunity, and professional climate, seem to make some difference in the cognitive aspect of burnout. The results indicated that even though personal commitment may draw service providers to the field and serve as a buffer to worker burnout, structural issues of chronic work overload and poor work environment exert deleterious effects and need to be addressed in the system as a whole to reduce staff burnout. One of the high priorities should be requiringa greater level of structured professional development and educational support such as provision of regular clinical supervision and training by qualified mental health professionals, given the fact that the workforce is inexperienced while the tasks at hand are uncharted and challenging. ${ }^{2,17,20}$ Highly structured and case-specific supervision and training has proven effective with young professionals. ${ }^{38}$

The second implication for practice is that the current study findings raised an awareness of STS as a serious job hazard to caregivers for North Korean refugees and called for systematic interventions to mitigate its deleterious effects on the workforce. Close emotional involvement with their clients may increase the susceptibility of service providers to STS. ${ }^{4,23}$ The study findings that STS is very prevalent among NK service providers and is closely related to worker burnout call for attention to the management of secondary traumatic stress at a system's level. They should include educational workshops to raise awareness of STS issues among clinical staff and organizational leaders, provision of well-structured clinical supervision and training for early identification of warning signs and teaching effective coping strategies, regular debriefing for difficult cases, and self-care skills training. ${ }^{5,18,39}$ Clinical supervision should deal with issues such as balancing trauma caseloads among staff, on-going assessment and monitoring of staff risk and provision of STS interventions.

The research implications of the current study are discussed. First, the current findings corroborate some previous studies' suggestion that three sub-constructs of MBI have differential explanatory power for worker burnout, and EE and DP are more closely correlated with each other than with PA. The findings support a suggestion that the two sub-constructs of EE and DP may be adequate and more appropriate to measure burnout. ${ }^{1,36}$ Second, the study outcomes provide empirical evidence that STS is a significant threat to the well-being and burnout of care givers for traumatized population and STS issue should be dealt with proactively to mitigate its effect on the staff morale and effectiveness.

The limitations of the present study need to be noted. First, the results of the current cross-sectional study are relational in nature; no inferences about causal relationships can be made. Second, cultural sensitivity of the instruments developed abroad might have affected the outcomes and validation studies for those instruments are in order. Despite the above-mentioned limitations, the present study is one of the few empirical studies that demonstrate the high level of burnout of service providers for North Korean refugees and identified protective and risk factors for burnout.

Considering the significant negative consequences of secondary traumatic stress to service providers working with traumatized populations, further research should be devoted to understanding factors that moderate the relationship between exposure to trauma victims and secondary traumatic stress. It is important to recognize this occupational hazard involved in service provision for traumatized individuals and to have preventive measures in place to mitigate the deleterious effects of working with traumatized populations.

\section{Acknowledgments}

This study was supported by the 2013 research grant of Daegu University.

\section{REFERENCES}

1. Maslach C, Schaufeli W, Leiter M. Job burnout. Ann Rev Psychol 2001; 52:397-422.

2. Boyas J, Wind L, Kang S. Exploring the relationship between employment-based social capital, job stress, burnout, and intent to leave among child protection workers: an age-based path analysis model. Child Youth Serv Rev 2012;34:50-62.

3. Bahner AD, Berkel LA. Exploring burnout in batterer intervention programs. J Interpers Violence 2007;22:994-1008.

4. Fourie L, Rothmann S, van de Vijver FJ. A model of work wellness for non-professional counselors in South Africa. Stress Health 2008;24:3547.

5. Bakker A, Van Der Zee K, Lewig K, Dollard M. The relationship between the big five personality factors and burnout: A study among volunteer counselors. J Soc Psychol 2006;146:31-50.

6. Iliffe G, Steed L. Exploring the counselor's experience of working with perpetrators and survivors of domestic violence. J Interpers Violence 2000;15:393-412. 
7. Devilly GJ, Wright R, Varker T. Vicarious trauma, secondary traumatic stress or simply burnout? Effect oftrauma therapy on mental health professionals. Aust N Z J Psychiatry 2009;43:373-385.

8. Figley CR. Compassion Fatigue as Secondary Traumatic Stress Disorder: An Overview. In: Figley FR, Editor. Compassion Fatigue: Coping with Secondary Traumatic Stress Disorder in Those Who Treat the Traumatized. New York: Brunner/Mazel, 1995, p.1-20.

9. The official count of North Korean refugees in South Korea. Available at http://www.unikorea.go.kr/content.do?cmsid=1440. Accessed May 20, 2016.

10. Heo SH, Lim GT, Seo YH. A Study on Economic Status of North Korean Defector Settlers in South Korea. North Korean Refugees Foundation; 2010.

11. KimYH, Cho YA,Yu SE. A study on the characteristics of poverty of North Korean settlers: A comparison with the South Korean poor. Korean J Soc Welfare 2009;69:195-218.

12. Jeon WT, Yu SE, Eom JS, Kim HJ. 7-year follow up study of adaptation of North Korean defectors: a focus on education and life. Korean Unification Stud 2009;13:127-157.

13. Kim YH. A study on North Korean Defectors' Mental Health. Doctoral dissertation, Seoul National University; 2006.

14. Yoon YS, Kim HA, Han YA. A study on burnout of North Korean service providers. Counsel Res 2007;8:877-898.

15. Hong SH, Park Y, Won M. Personal characteristics of North Korean defectors that are hindrance to their adaptation to South Korea and job demands on protection officers: protection officers' perspective. J Korean Soc Welfare 2003;52:223-240.

16. Kim YH, Kim YK. A study on influencing factors of job satisfaction of service providers for North Korean refugees. Soc Sci Res 2012;23:23-58.

17. Demerouti E, Bakker AB, Nachreiner F, Schaufeli WB. The Job demands-resources model of burnout. J Appl Psychol 2001;86:499-512.

18. Spence Laschinger HP, Grau AL, Finegan J, Wilk P. Predictors of new graduate nurses' workplace well-being: testing the job demands-resources model. Health Care Manage Rev 2012;37:175-186.

19. Kadambi MA, Truscott D. Vicarious traumatization and burnout among therapists working with sex offenders. Traumatology 2003;9:216-230.

20. Nho C, Joo H, Son YK. Effects of individual and organizational characteristics and vicarious trauma on burnout among counselors working with sex workers. Ment Health Soc Work 2008;28:265-293.

21. Maslach C, Leiter M. Early predictors of job burnout and engagement. J Appl Psychol 2008;93:498-512.

22. Figley CR. Compassion Fatigue: Toward a New Understanding of the Costs of Caring. In: Stamm BH, Editor. Secondary Traumatic Stress: Self-Care Issues for Clinicians, Researchers, and Educators (2nd Ed.). Lutherville, MD: Sidran, 1999, p.3-28.

23. Pearlman LA, Saakvitne KW. Trauma and the therapist: countertrans- ference and vicarious traumatization in psychotherapy. Res Pract 1995; 26:558-565.

24. Bride B, Robinson M, Yegidis B, Figley C. Development and validation of the secondary traumatic stress scale. Res Soc Work Pract 2004;14: 27-35.

25. Figley CR, Kleber RJ. Beyond the "Victim": Secondary Traumatic Stress. In: Kleber RJ, Figley CR, Gersons B, Editors. Beyond Trauma: Cultural and Societal Dynamics. New York: Plenum Press, 1995, p.75-98.

26. Aguilera DC. Crisis Intervention: Theory and Methodology (8th Ed.). St. Louis, MO: Mosby-Year Book; 1998

27. Sprang G, Craig C, Clark J. Secondary traumatic symptoms and burnout in child welfare workers: a comparative analysis of occupational distress across professional groups. Child Welfare 2011;90:149-168.

28. Kim BJ, Lee KM. The relationship between job demands, social support and employee's reactions. Korean J Bus Admin 2009;22:2187-2206.

29. Ballenger-Browining KK, Schmitz KJ, Rothacker JA, Hammer PS, Webb-Murphy JA, Johnson DC. Predictors of burnout among military mental health providers. Mil Med 2011;176:253-260.

30. Rubin A, Babbie E. Research Methods for Social Work. Belmont, CA: Thomson/Brooks; 2010.

31. Jayaratne $\mathrm{S}$, ChessWA. The effect of emotional support on perceived job stress and strain. J Appl Behav Sci 1984;20:141-153.

32. Baek KH. A Study on Burnout of the Social Workers Working at Shelters for Domestic Violence Victims. Master's Thesis, Catholic University; 2004.

33. Park JY. Psychometric properties of the Korean version of secondary traumatic symptoms scale (K-STSS). Korean J Soc Welfare 2011;63: 33-57.

34. Porter LW, Steers RM, Mowday RT, Boulian PV. Organizational commitment, job satisfaction, and turnover among psychiatric technicians. J Appl Psychol 1974;59:603-615.

35. Kim SH. A Study on the Determinants of Intent to Leave among Social Workers. Doctoral dissertation, Seoul National University; 1997.

36. Maslach C, Leiter MP. The Truth about Burnout: How Organizations Cause Personal Stress and What to Do about It. San Francisco, CA: Jossey Bass; 1997.

37. Pearlman LA. Self-Care for Trauma Therapists: Ameliorating Vicarious Traumatization. In: Stamm BH, Editor. Secondary Traumatic Stress: Self-Care Issues for Clinicians, Researchers, and Educators (2nd Ed): Lutherville, MD: Sidran, 1999, p.51-64.

38. Joubert L, Hocking A, Hampson R. Social Work in Oncology- Managing Vicarious Trauma- The Positive Impact of Professional Supervision. Soc Work Health Care 2013;52:238-252.

39. Salston M, Figley C. Secondary traumatic stress effects of working with survivors of criminal victimization. J Trauma Stress 2003;16:167-174 